\title{
Isolation of Chlamydia trachomatis from eye secretion (tears)
}

\author{
S. DAROUGAR, T. FORSEY, B. R. JONES, J. Allami, ${ }^{1}$ and A. HOUSHMAND \\ From the Virus Laboratory, Department of Clinical Ophthalmology, Institute of Ophthalmology, \\ Judd Street, London, and the ${ }^{1}$ School of Public Health, University of Teheran, PO Box 1310, Teheran, Iran
}

SUMMARY Shedding of Chlamydia trachomatis in the eye secretion (tears) of patients with either hyperendemic trachoma or paratrachoma was studied. The method of collection of eye secretion with cellulose sponges is proved to be simple, faster, and more practicable and yielded a higher rate of chlamydial isolation than aspiration. The chlamydial isolation rates in eye secretion in chlamydia-positive paratrachoma patients in London or trachoma patients in Iran was 84 and $49 \%$ respectively. It was found that the chlamydial isolation rate from eye secretion is directly related to the number of inclusions present in the conjunctival swabbings. The results of this study indicated that patients with moderate to severe hyperendemic trachoma or paratrachoma are the main reservoir of infection. In the developing countries of the Middle East and Africa the shedding of chlamydia in the eye secretion of persons with these diseases is a major factor in the transmission of them by means of flies, fingers, towels, or bed clothes.

Hyperendemic trachoma is commonly transmitted from eye to eye in circumstances which involve frequent contacts between eyes or the discharge therefrom (Jones et al., 1976). Flies, fingers, towels bed-clothes, and other clothes are considered to have an important role in the transmission of hyperendemic trachoma. Recently Jones et al. (1976) demonstrated that flies can transmit fluoresceinlabelled eye discharges from the eyes of one child to the eyes of adjacent children with remarkable speed and precision.

Paratrachoma of sexually transmitted origin (inclusion conjunctivitis, TRIC punctate keratoconjunctivitis, and endemic trachoma), which is prevalent in the urban communities of developed countries, is commonly transmitted from the genital tract to the eye and only rarely by eye to eye transmission (Jones, 1964).

The present investigation was undertaken to provide quantitative data on the shedding of Chlamydia trachomatis in the eye secretion (tears) of patients with either hyperendemic trachoma or paratrachoma and to examine the correlation with the presence of viable chlamydia in the conjunctiva.

Address for reprints: Dr S. Darougar, Department of Clinical Ophthalmology, Institute of Ophthalmology, Judd Street, London WC1H 9QS
Patients and methods

SELECTION OF PATIENTS

Patients included in this study were those attending the External Eye Disease Clinic, Moorfields Eye Hospital, London, with acute follicular conjunctivitis suggestive of paratrachoma, and the inhabitants of 3 villages in southern Iran with various grades of active trachomatous inflammatory changes or inactive hyperendemic trachoma.

COLLECTION OF EYE SECRETIONS AND

CONJUNCTIVAL SWABBINGS

In all cases eye secretion was collected before conjunctival swabbings. In the first 28 consecutive London cases eye secretion from both eyes was collected by aspiration with glass capillary tubes, then were suspended in a plastic capsule containing 2SP transport medium (Gordon et al., 1969) with additional $3 \%$ fetal calf serum, and stored in a liquid nitrogen refrigerator $\left(-180^{\circ} \mathrm{C}\right)$. The amount of eye secretion collected from both eyes in this way was approximately $0.1 \mathrm{ml}$ in each case.

In a further 20 London cases and in all patients in 3 villages in Iran eye secretion was collected by cellulose sponges (Spontex Ltd., Croydon, Surrey, England) measuring $5 \times 3 \times 1 \mathrm{~mm}$. One sponge was placed in the lower fornix of the conjunctiva of 
each eye and allowed to become saturated with secretion. Sponges collected from the left and right eyes were placed together in one plastic capsule containing transport medium and stored in a liquid nitrogen refrigerator. The amount of eye secretion collected by sponges from the left and right eye together was approximately $0.1 \mathrm{ml}$.

After collection of eye secretion conjunctival swabbings were collected from the whole conjunctiva (upper tarsus, upper fornix, and lower lid) of the right and left eyes as described previously (Darougar and Jones, 1971). The paired swabbings from the right and left eyes were pooled in a plastic capsule containing transport medium and stored at $-180^{\circ} \mathrm{C}$.

\section{ISOLATION TEST}

The simplified one-passage technique of culture in irradiated McCoy cells (Darougar et al., 1971) was used for isolation of chlamydia from eye secretion and conjunctival swabbings. Each specimen was inoculated into 2 tubes. Of these, 1 tube was fixed after approximately 60 hours' incubation, stained with Giemsa stain, and examined by dark-field illumination. The number of inclusions identified in this tube was recorded. The second tube was harvested and repassaged for serotyping of the isolates.

\section{Results}

In London the eye secretions from 28 consecutive patients were collected by aspiration and from a further 20 patients by cellulose sponges. In those patients with positive conjunctival swabbings the Chlamydia trachomatis isolation rate in eye secretions collected by aspiration or sponges was 75 and $100 \%$ respectively (Table 1 ).

Conjunctival swabbings and eye secretions were collected in parallel from a total of 752 patients in Iran. In these patients $C$. trachomatis was isolated in conjunctival swabbings in $57(8 \%)$ and in eye secretion in $28(4 \%)$ (Table 2$)$.

In cases of paratrachoma the average numbers of inclusions obtained in conjunctival swabbings and in eye secretion were 436 and 75 respectively (Table 2). In 32 paratrachoma patients with positive conjunctival swabbings the eye secretion was negative in $5(16 \%)$.

In 57 trachoma patients with positive conjunctival swabbings the eye secretion was negative in $32(56 \%)$. In the trachoma group the eye secretion was positive in 3 patients whereas the conjunctival swabbings were negative. The average number of inclusions obtained in conjunctival swabbings and in eye secretions in these patients are shown in Table 2.

The isolation rate of $C$. trachomatis in eye secretion
Table 1 Isolation of $\mathrm{C}$. trachomatis from eye secretion collected by aspiration or sponges and compared with isolation from conjunctival swabbings in patients with paratrachoma in London

\begin{tabular}{llll}
\hline $\begin{array}{l}\text { Method of } \\
\text { collection }\end{array}$ & $\begin{array}{l}\text { No. of } \\
\text { patients }\end{array}$ & $\begin{array}{l}\text { No. of positive } \\
\text { swabbings }\end{array}$ & $\begin{array}{l}\text { No. of positive } \\
\text { eye secretion }\end{array}$ \\
\hline Aspiration & 28 & 20 & $15(75 \%)$ \\
Sponges & 20 & 12 & $12(100 \%)$ \\
\hline
\end{tabular}

Table 2 Isolation of $\mathrm{C}$. trachomatis from eye secretion and conjunctival swabbings from patients with paratrachoma in London and hyperendemic trachoma in Iran

\begin{tabular}{|c|c|c|c|c|c|}
\hline \multirow[b]{2}{*}{ Area } & \multirow[b]{2}{*}{$\begin{array}{l}\text { No. of } \\
\text { patients }\end{array}$} & \multicolumn{2}{|l|}{$\begin{array}{l}\text { No. of } \\
\text { positives }\end{array}$} & \multicolumn{2}{|c|}{$\begin{array}{l}\text { Average No. of } \\
\text { inclusions }\end{array}$} \\
\hline & & $\begin{array}{l}\text { Eye } \\
\text { secretion }\end{array}$ & $\begin{array}{l}\text { Conjunc. } \\
\text { swab }\end{array}$ & $\begin{array}{l}\text { Eye } \\
\text { secretion }\end{array}$ & $\begin{array}{l}\text { Conjunc. } \\
\text { swab }\end{array}$ \\
\hline London & 48 & $27(56 \%)$ & $32(67 \%)$ & 75 & 436 \\
\hline Iran & 752 & $28(4 \%)$ & $57(8 \%)$ & 11 & 355 \\
\hline
\end{tabular}

Table 3 Chlamydial isolation rate in eye secretion in relation to the number of inclusions obtained from conjunctiva

\begin{tabular}{llc}
\hline $\begin{array}{l}\text { No. of } \\
\text { patients }\end{array}$ & $\begin{array}{l}\text { No. of inclusions by swabbing } \\
\text { (per patient) }\end{array}$ & $\begin{array}{l}\text { No. of positive } \\
\text { eye secretion }\end{array}$ \\
\hline 12 & Over 1000 & $9(75 \%)$ \\
31 & $101-1000$ & $19(61 \%)$ \\
33 & $11-100$ & $20(61 \%)$ \\
13 & $1-10$ & $4(31 \%)$ \\
\hline
\end{tabular}

correlated well with the number of infectious chlamydial particles obtained from the conjunctiva by swabbings. In patients with over 1000 inclusions from culture of their conjunctival swabbings the eye secretion was positive in $75 \%$, whereas in those with fewer than 10 inclusions from culture of their conjunctival swabbings this rate was only $31 \%$ (Table 3).

\section{Discussion}

In the present study the eye secretion was collected by aspiration in capillary tubes in the first 28 cases of paratrachoma. We found this method to be tedious, time-consuming, and hardly practicable. Alternatively, we used cellulose sponges for collection of eye secretion. This method is being used successfully in our laboratory and field work for detection of antichlamydial antibody in eye secretion (Treharne et al., 1977; Darougar et al., 
1978). This method proved to be simple, faster, and more practicable for collection of eye secretion and yielded a higher rate of chlamydial isolation than did aspiration.

The chlamydial isolation rate in eye secretion in patients with positive culture (by swabbing) for C. trachomatis in London and in Iran was 27 out of $32(84 \%)$ and 28 out of $57(49 \%)$ respectively. This difference may be related to the degree of intensity of inflammatory changes in the conjunctiva and the number of inclusions present in the conjunctiva or the amount of eye discharge.

Darougar et al. (1977) have shown that the chlamydial isolation rate from conjunctiva is generally related to the intensity of inflammatory changes in the eye. In London and in Tunisia in patients with clinically diagnosed moderate to severe paratrachoma or trachoma the isolation rate for C. trachomatis was 90 and $73 \%$ respectively, whereas in patients with mild trachoma this rate was as low as $23 \%$ (Darougar et al., 1977).

In the present study we found that the chlamydial isolation rate from eye secretion is directly related to the number of inclusions present in the conjunctiva as demonstrated by isolation tests from conjunctival swabbings. In patients with an average number of 1000 inclusions or more from their conjunctival swabbings the isolation rate in eye secretion was as high as $75 \%$, but in those patients with an average number of 1 to 10 inclusions the eye secretion was positive in only $31 \%$ (Table 3 ).

The result of this study indicates that patients with moderate to severe hyperendemic trachoma or paratrachoma are the main reservoir of infectious agent being shed from the eyes. They are harbouring more infectious agent and are shedding greater numbers of viable particles in their eye secretion. It is also possible that the excess amount of mucoid discharge in the eye of these patients may have an important role in protecting chlamydia from adverse effects of environmental factors.

In the developing countries of the Middle East and Africa the shedding of chlamydia in eye secretion of patients with moderate to severe trachoma is a major factor in transmission of the disease by means of flies, fingers, towels, or bedclothes. In London, although shedding of chlamydia in eye secretion is common, the eye to eye transmission of the disease is rare (Jones, 1964). This, in general, is due to higher standards of personal and ocular hygiene and the absence of eye-seeking flies in the community.

In eye secretion antichlamydial antibody has been found in $85 \%$ of patients with paratrachoma
(Darougar et al., 1978), and in up to $47 \%$ of patients with moderate to severe hyperendemic trachoma (Treharne et al., in preparation). Barenfanger and MacDonald (1974) have shown that eye secretions with antitrachoma antibody neutralise the trachoma agent. However, isolation of chlamydia in eye secretion may suggest that in the patients' eyes antichlamydial antibodies may have little or no effect on chlamydia.

The authors are grateful to Professors A. Nadim and F. Modabber, School of Public Health, Teheran University, and to the Director of the Department of Health and Welfare, Bandar Abbas, Iran, for their assistance in the organisation of field work, to $\mathrm{Mr} \mathrm{H}$. Shah-Mohamadi and Mr Gh. Farahmandian, and to colleagues in the External Eye Disease Clinic, Moorfields Eye Hospital, for their assistance in collection of specimens.

The laboratory work was supported by grants from an anonymous donor, the Department of Health and Social Security, and the World Health Organisation.

\section{References}

Barenfanger, J., and MacDonald, A. B. (1974). The role of immunoglobulin in the neutralisation of trachoma infectivity. Journal of Immunology, 113, 1607-1617.

Darougar, S., and Jones, B. R. (1971). Conjunctival swabbing for the isolation of TRIC agent (Chlamydia). British Journal of Ophthalmology, 55, 585-590.

Darougar, S., Kinnison, J. R., and Jones, B. R. (1971). Simplified irradiated McCoy cell culture for isolation of Chlamydia. In Trachoma and Related Disorders Caused by Chlamydial Agents, pp. 63-70. Edited by R. L. Nichols. Excerpta Medica: Amsterdam.

Darougar, S., Treharne, J. D., Minassian, D., El Sheikh, H., Dines, R. J., and Jones, B. R. (1978). Rapid serological test for diagnosis of chlamydial ocular infections. British Journal of Ophthalmology, 62, 503-508.

Darougar, S., Woodland, R. M., Forsey, T., Cubitt, S., Allami, J., and Jones, B. R. (1977). Isolation of Chlamydia from ocular infections. In Non-gonococcal Urethritis and Related Infections, pp. 295-298. Edited by D. Hobson and K. K. Holmes. American Society for Microbiology: Washington, DC.

Gordon, F. B., Harper, I. A., Quan, A. L., Treharne, J. D., Dwyer, R. St. C., and Garland, J. A. (1969). Detection of Chlamydia (Bedsonia) in certain infections of man. 1. Laboratory procedures: Comparison of yolk sac and cell culture for detection and isolation. Journal of Infectious Diseases, 120, 451-462.

Jones, B. R. (1964). Ocular syndromes of TRIC virus infection and their possible genital significance. British Journal of Venereal Diseases, 40, 3-18.

Jones, B. R., Darougar, S., Mohsenine, H., and Poirier, R. H. (1976). Communicable ophthalmia: the blinding scourge of the Middle East. British Journal of Ophthalmology, 60, $492-498$.

Treharne, J. D., Dines, R. J., and Darougar, S. (1977). Serological responses to chlamydial ocular and genital infection in the United Kingdom and the Middle East. In Non-gonococcal Urethritis and Related Infections, pp. 249-258. Edited by D. Hobson and K. K. Holmes. American Society for Microbiology: Washington, DC. 